\title{
Morphological pattern of Crista terminalis, Musculi pectinati and Taenia sagittalis with applied significance
}

\author{
RASTOGI, R. ${ }^{1}$, BUDHIRAJA, V. ${ }^{1}$, JAIN, S. K. ${ }^{1}$, SHARMA, N. ${ }^{1}$, \\ GARG, R. ${ }^{1}$ and NAFEES, H. ${ }^{1}$
}

\author{
${ }^{1}$ Department of Anatomy, Teerthanker Mahaveer Medical College Moradabad, India \\ *E-mail: rakhirastogil207@gmail.com
}

\begin{abstract}
Introduction: Crista terminalis is a fibromuscular vertical ridge of smooth myocardium within the right atrium of the heart. Material and Methods: We examined eighty human hearts obtained from the cadaver to see morphological pattern of Crista terminalis, Musculi pectinati and Taenia sagittalis. In $40 \%$ cases musculi pectinati oriented perpendicular to the Crista terminalis followed by Parallel in $18.75 \%$. We also observed single and multiple trunks of Taenia sagittalis in $56.25 \%$ and $6.25 \%$ cases respectively. In the present study we tried to provide a guideline of gross morphological arrangement of principal muscular bundles for the interventional operator so that they have precise anatomical information prior to interventional procedure.
\end{abstract}

Keywords: crista terminalis, musculi pectinati, taenia sagittalis.

\section{Introduction}

The Crista terminalis (CT) is a fibromuscular vertical ridge of smooth myocardium within the right atrium of the heart (HO, ANDERSON and SÁNCHEZ-QUINTANA, 2002). It is located on the posterolateral wall of the chamber. It extends between the right side of the orifice of the Superior vena cava inferiorly to the right side of the valve of Inferior vena cava. CT is an important landmark due to its close association with sinoatrial nodal artery and the origin of the musculi pectinati (MP). The MP is muscular ridges that extend anterolaterally from the CT to reach the auricle and may present in a number of variable forms and shapes/sizes. The largest and most prominent MP forming the bridge of the sulcus terminalis internally is called Taenia sagittalis (TS), literally meaning sagittal worm (LOUKAS, TUBBS, TONGSON et al., 2008). The echocardiographic finding of a prominent crista terminalis can mimic a right atrial mass, such as a tumor or thrombus (D'AMATO, PIERFELICE and D'AGOSTINO, 2009; GAUDIO, DI MICHELE, CERA et al., 2004). Thus, an understanding of the anatomy and proper identification helps in avoiding misdiagnosis (SALUSTRI, BAKIR, SANA et al., 2010). Taking into consideration that only few studies are there to analyze the gross features of MP in relation to CT, this study was planned and executed to describe the morphologic patterns of the MP and TS (LOUKAS, TUBBS, TONGSON et al., 2008).

\section{Material and Methods}

We examined eighty human hearts from the cadaver received in the department of Anatomy of Teethanker Mahaveer Medical College. To visualize the CT and MP the superior vena cava (SVA) and Inferior vena cava (IVC) were cut open posteriorly along a linear axis, thus exposing the right atrium. A second incision was made perpendicular to the original cut, parallel to coronary sulcus. This was done to preserve the near normal morphology of the CT and the MP.

\section{Results}

CT was present in all 80 specimens. Variations of morphological pattern of MP and TS observed and recorded. To facilitate the proper understanding of variable patterns, the results were classified in accordance with Siddiqui, Daimi, Gandhi et al. (2013). Observations on MP. The pattern of MP was classified into six patterns

(1) Type 1-MP oriented perpendicular to the CT with equidistant spacing (Figure 1)

(2) Type 2-MP oriented Parallel to the CT with equidistant spacing (Figure 2)

(3) Type 3-Combination of type 1 and type 2 with more than one common muscular trunk (Figure 3)

(4) Type 4-Branching of the MP (Figure 4)

(5) Type 5- Interlacing trabeculations, nonuniform MP organized in a haphazard, and trabecular pattern with numerous crossovers (Figure 5)

(6) Type 6- Prominent muscular columns of MP (Figure 6)

Most common pattern observed was Type- 1 followed by Type -2. Results are summarized in Table 1

(A) Observations on TS. The TS was classified into three Types.

(1) Type A- TS absent (Figure 1)

(2) Type B- Single trunk of TS (Figure 7)

(3) Type C-Multiple trunks of TS (Figure 8)

In majority of cases there were single TS. Results are summarized in Table 2 


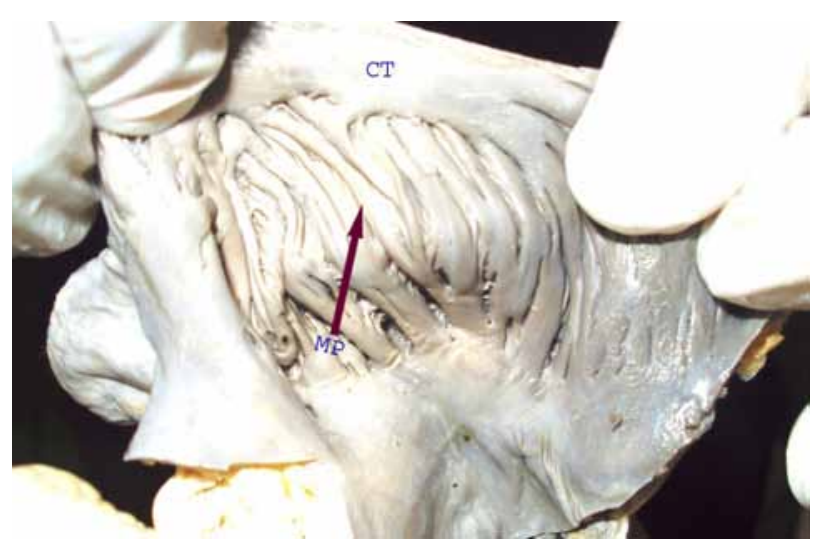

Figure 1. Showing musculi pectinati oriented perpendicular to the Crista terminalis. MP - musculi pectinati; CT - Crista terminalis.

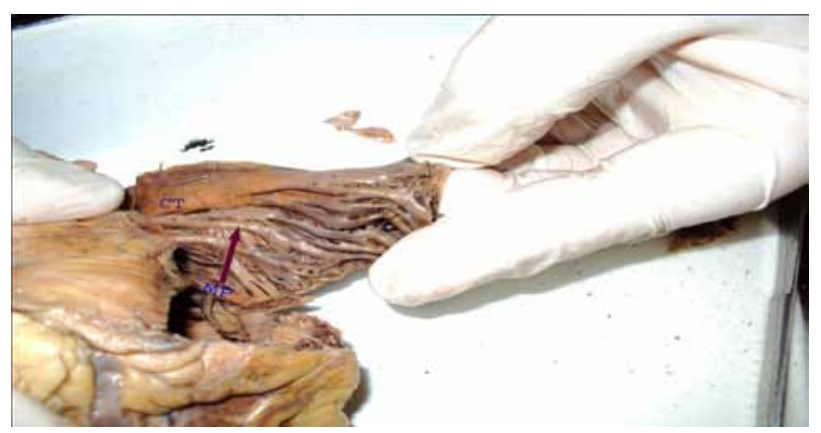

Figure 2. Showing musculi pectinati oriented parallel to the Crista terminalis. MP - musculi pectinati; CT - Crista terminalis.

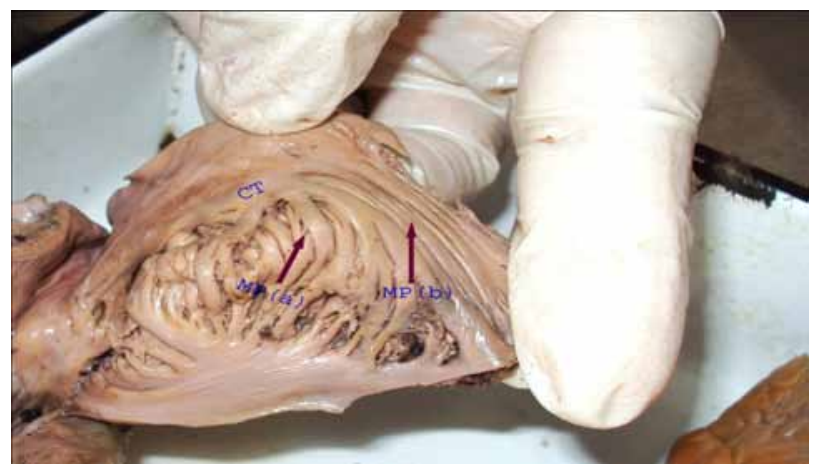

Figure 3. Showing musculi pectinati oriented perpendicular \& parallel to the Crista terminalis. MP (a) - perpendicular musculi pectinati; MP (b) - parallel musculi pectinati; CT - Crista terminalis.

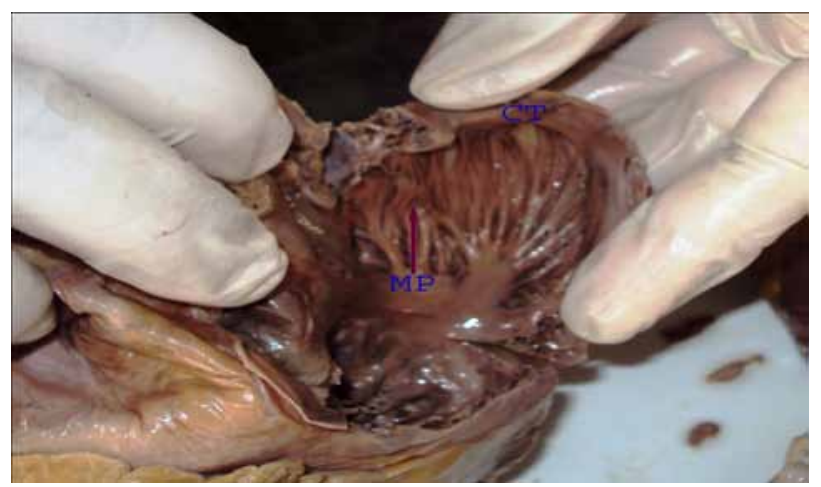

Figure 4. Showing branching musculi pectinati. MP - musculi pectinati; CT - Crista terminalis.

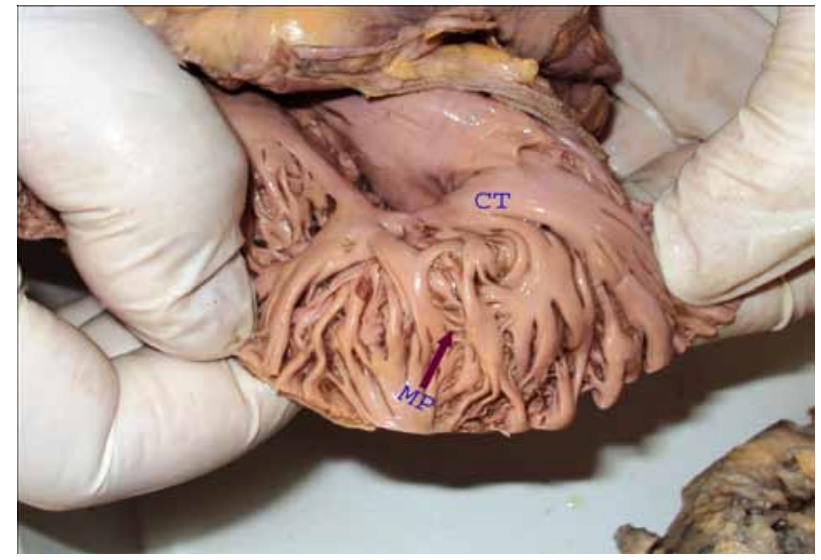

Figure 5. Showing interlacing trabeculations, nonuniform MP organized in a haphazard, and trabecular pattern with numerous crossovers MP - musculi pectinati; CT- Crista terminalis.

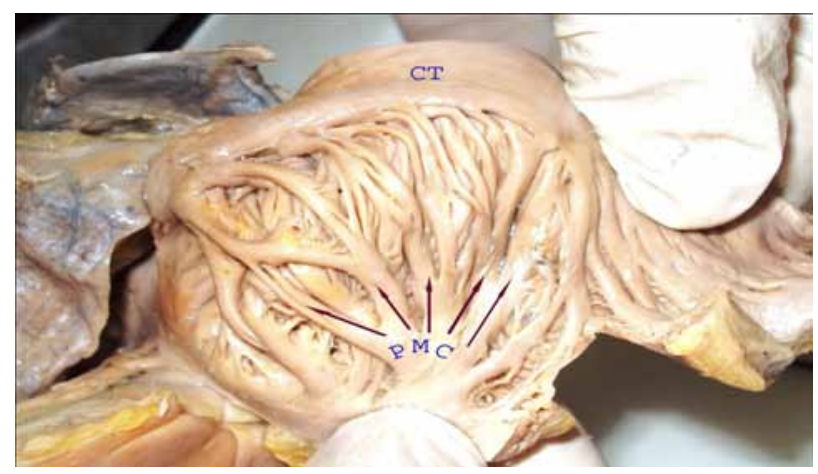

Figure 6. Showing Prominent muscular columns of musculi pectinati. CT - Crista terminalis; PMC - Prominent muscular columns.

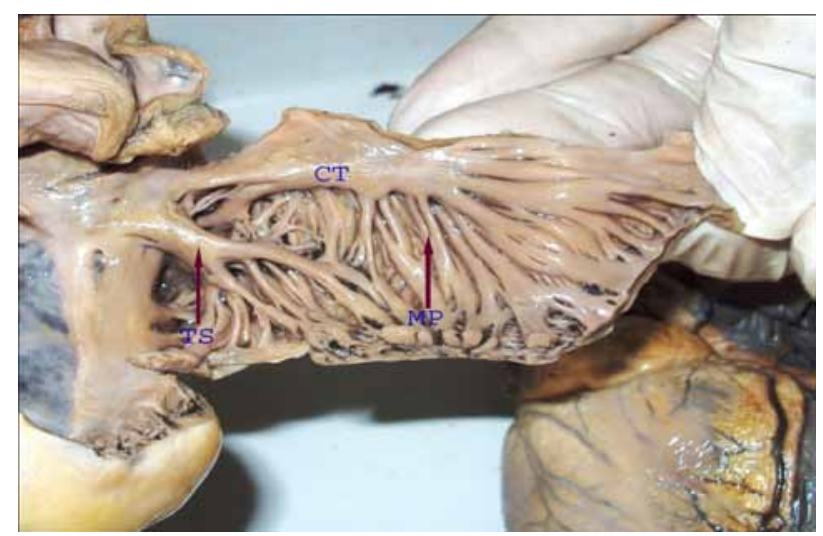

Figure 7. Showing Single trunk of Taenia sagittalis. TS - Taenia sagittalis; CT - Crista terminalis; MP - musculi pectinati.

\section{Discussion}

Dysfunction of atria is a common pathology of heart which may accompany with severe cardiac diseases. A better understanding of fundamental mechanisms underlying atrial function and dysfunction is of great benefit to therapeutic approaches. Anatomical structure, interatrial coupling, fast conduction bundles and electrophysiological heterogeneity seem to play an important role for atrial excitation conduction 


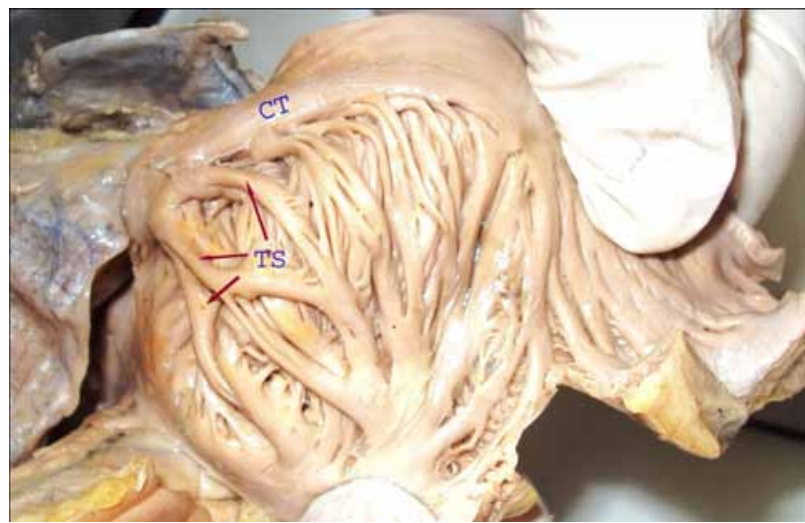

Figure 8. Showing Multiple trunks of Taenia sagittalis. TS - Taenia sagittalis; CT - Crista terminalis.

Table 1. Patterns for MP $(n=80)$.

\begin{tabular}{ccc}
\hline Pattern observed & $\begin{array}{c}\text { No of Hearts } \\
\text { Sample }\end{array}$ & Percentage (\%) \\
\hline Type-1 & 32 & $40 \%$ \\
Type-2 & 15 & $18.75 \%$ \\
Type-3 & 14 & $17.50 \%$ \\
Type-4 & 8 & $10 \%$ \\
Type-5 & 7 & $8.75 \%$ \\
Type-6 & 4 & $5 \%$ \\
\hline
\end{tabular}

Table 2. Patterns for TS $(n=80)$.

\begin{tabular}{ccc}
\hline Pattern observed & $\begin{array}{c}\text { No of Hearts } \\
\text { Sample }\end{array}$ & Percentage (\%) \\
\hline Type A & 30 & $37.5 \%$ \\
Type B & 45 & $56.25 \%$ \\
Type C & 5 & $6.25 \%$ \\
\hline
\end{tabular}

during physiological and pathological conditions. The most important anatomical structures for initiation and conduction of atrial excitation are sinoatrial node, the CT, MP and the interatrial connections. Understanding atrial electromechanical function requires knowledge of anatomy, electrophysiology and excitation conduction. The detailed model of human atria provides a useful and complementary tool to investigate the dynamical behavior of atria (SEEMANN, HOPER, SACHSE et al., 2009).

The complexity of atrial geometry dictates that the spread of activation from the site of origin of the cardiac impulse will be restrained by naturally occurring barriers and orifices. It has been shown physiologically that the CT provides barrier to conduction transversely across it during typical atrial flutter (OLGIN, KALMAN, FITZPATRICK et al., 1995; SCHUMACHER, JUNG, SCHMIDT et al., 1999). Although the barrier at the CT is considered anatomically fixed, mapping studies in animal models have shown transverse conduction across the CT in the normal hearts (ORTIZ, NIWANO, ABE et al., 1994). Mizumaki, Fujiki, Nagasawa et al. (2002) correlated the greater diameter of CT with occurrence of atrial flutter, There are also studies suggesting that structural abnormalities of the CT and MP may be the primary abnormality in atrial flutter patients with grossly normal atria
(OLGIN, KALMAN, FITZPATRICK et al., 1995; ELLIS, SIPPENSGROENEWEGEN, AUSLANDER et al., 2000).

Orientation of fibers from the CT and MP forms an anatomic/electrophysiological basis for intercaval block. MP with highly trabeculated muscle fibers may facilitate the nonuniform spread of the excitatory impulse. Due to this arrangement of muscle bundles, the patient is predisposed to several arrhythmias. Wu, Yashima, Xie et al. (1998) Postulated that large MP ridges provide a natural substrate for the initiation of intra-atrial reentry and prolong the life spans of reentrant wave front, thus determining "flutter-like" or "fibrillation-like" activity, respectively, in isolated canine atrial tissue. In the present study we also observed prominent muscular column of MP in $5 \%$ cases. Practically the most common ways of treating atrial flutter is the use of radiofrequency catheter ablation. It is during this ablation procedure the morphology of MP is pertinent as it carries risk of iatrogenic myocardial injury especially in Type $6 \mathrm{MP}$, Type B TS and Type C TS (SIDDIQUI, DAIMI, GANDHI et al., 2013).

In the present study we tried to provide a guideline of gross morphological arrangement of principal muscular bundles for the interventional operator so that they have precise anatomical information prior to interventional procedure as Type $6 \mathrm{MP}$, Type $\mathrm{B}$ and Type $\mathrm{C}$ TS have more complex arrangements of fibers and tendency to be damaged during cardiac catheterization.

\section{References}

D'AMATO, N., PIERfElice, C. and D'AGOSTINO, C. Crista terminalis bridge: a variant mimicking right atrial mass. European Journal of Echocardiography, 2009, vol. 10, n. 3, p. 444-445. PMid:19074158. http://dx.doi.org/10.1093/ejechocard/jen316.

ELLIS, WS., SIPPENSGROENEWEGEN, A., AUSLANDER, DM. and LESH, MD. The role of the crista terminalis in atrial flutter and fibrillation: a computer modeling study. Annals of Biomedical Engineering, 2000, vol. 28, n. 7, p. 742-754. PMid:11016412. http://dx.doi.org/10.1114/1.1289456.

GAUdio, C., Di MICHELE, S., CERA, M., NGUYEN, BL., PANNARALE, G. and ALESSANDRI, N. Prominent Crista terminalis mimicking a right atrial Mixoma: cardiac magnetic resonance aspects. European Review for Medical and Pharmacological Sciences, 2004, vol. 8, n. 4, p. 165-168. PMid:15636402.

HO, SY., ANDERSON, RH. and SÁNCHEZ-QUINTANA, D. Gross structure of the atriums: more than an anatomic curiosity? Pacing and Clinical Electrophysiology, 2002, vol. 25, n. 3, p. 342-350. PMid:1 1990664. http://dx.doi.org/10.1046/j.14609592.2002.00342.x.

LOUKAS, M., TUBBS, RS., TONGSON, JM., POLEPALLI, S., CURRY, B., JORDAN, R. and WAGNER, T. The clinical anatomy of the crista terminalis, pectinate muscles and the teniae sagittalis. Annals of Anatomy, 2008, vol. 190, n. 1, p. 81-87. PMid:18342146. http://dx.doi.org/10.1016/j.aanat.2007.05.002.

MIZUMAKI, K., FUJIKI, A., NAGASAWA, H., NISHIDA, K., SAKABE, M., SAKURAI, K. and INOUE, H. Relation between transverse conduction capability and the anatomy of the crista terminalis in patients with atrial flutter and atrial fibrillation, Analysis by intracardiac Echocardiography. Circulation Journal, 2002, vol. 66, n. 12, p. 1113-1118. PMid:12499616. http://dx.doi.org/10.1253/ circj.66.1113.

OLGIN, JE., KALMAN, JM., FITZPATRICK, AP. and LESH, MD. Role of right atrial endocardial structures as barriers to conduction during human type I atrial flutter: activation and entrainment mapping 
guided by intracardiac echocardiography. Circulation, 1995, vol. 92, n. 7, p. 1839-1848. PMid:7671368. http://dx.doi.org/10.1161/01. CIR.92.7.1839.

ORTIZ, J., NIWANO, S., ABE, H., RUDY, Y., JOHNSON, NJ. and WALDO, AL. Maping the conversion of atrial flutter to atrial fibrillation and atrial fibrillation to atrial flutter, Insights into mechanisms. Circulation Research, 1994, vol. 74, n. 5, p. 882-894. PMid:8156635. http://dx.doi.org/10.1161/01.RES.74.5.882.

SALUSTRI, A., BAKIR, S., SANA, A., LANGE, P. and MAHMEED, WA. Promiment Crista terminalis mimicking a right atrial mass: case report. Cardiovascular Ultrasound, 2010, vol. 8, p. 47. http://dx.doi. org/10.1186/1476-7120-8-47.

SCHUMACHER, B., JUNG, W., SCHMIDT, H., FISCHENBECK, C., LEWALTER, T., OMRAN, H. and HAGENDORFF, A. Transverse conduction capabilities of the crista terminalis in patients with atrial flutter and fibrillation. Journal of the American College of Cardiology, 1999, vol. 34, n. 2, p. 363-373. PMid:10440147. http://dx.doi. org/10.1016/S0735-1097(99)00211-9.

SEEMANN, G., HOPER, C., SACHSE, FB., DOSSEL, O., HOLDEN, AV. and ZHANG, H. Heterogeneous three-dimensional anatomical and electrophysiological model of human atria. Philosophical Transaction of the Royal Society A, 2009, vol. 364, n. 1843, p. 14651481. PMid:16766355.

SIDDIQUI, AU., DAIMI, SRH., GANDHI, KR., SIDDIQUI, AT., TRIVEDI, S., SINHA, MB. and RATHORE, M. Crista terminalis, Musculi pectinati and Taenia Sagittalis: anatomical observations and applied significance. ISRN Anatomy, 2013, vol. 2013, p. 803853. http://dx.doi.org/10.5402/2013/803853.

WU, TJ., YASHIMA, M., XIE, F., ATHILL, CA., KIM, YH., FISHBEIN, MC., GARFINKEL, A., WEISS, JN., KARAQUEUZIAN, HS. and CHEN, PS. Role of pectinate muscle bundles in the generation and maintenance of intra-atrial reentry: potential implications for the mechanism of conversion between atrial fibrillation and atrial flutter. Circulation Research, 1998, vol. 83, n. 4, p. 448-462. PMid:9721702. http://dx.doi.org/10.1161/01.RES.83.4.448.

Received August 12, 2015 Accepted October 28, 2016 